\title{
Effectiveness of single injection sub-Tenon's block for Pars Plana Vitrectomy and associated procedures
}

\author{
Chandra Mohan Kumar ${ }^{*}$, Edwin Seet ${ }^{1}$, Joselo Macachor ${ }^{2}$, Bakthavatsalu Maheshwar ${ }^{3}$, Audris Chia ${ }^{4}$ \\ ${ }^{1}$ Senior Consultant in Anaesthesia, Khoo Teck Puat Hospital, Singapore \\ ${ }^{2}$ Clinical Associate in Anaesthesia, Khoo Teck Puat Hospital, Singapore \\ ${ }^{3}$ Senior Staff Physician, Department of Ophthalmology, Khoo Teck Puat Hospital, Singapore \\ ${ }^{4}$ Research Nurse, Department of Anaesthesia, Khoo Teck Puat Hospital, Singapore
}

\begin{abstract}
Background and objective: To determine the efficacy of a single injection sub-Tenon's block for Pars Plana Vitrectomy (PPV).

Patients and methods: Anaesthetic records and operative databases of patients undergoing PPV and associated procedures who received single injection inferotemporal sub-Tenon's block with $6 \mathrm{mls}$ of $2 \%$ lignocaine and $10 \mathrm{IU} / \mathrm{ml}$ hyaluronidase were identified. Onset of surgical anaesthesia, surgery duration, intraoperative discomfort, time and number of supplementary injections, sedation administered and any complications were extracted

Results: Sixty-four records were identified. All patients were ready for surgery within 8 minutes. The time of block to start of surgery was 17 ( \pm 6 ) minutes. Mean duration of surgery was $88( \pm 30)$ minutes, $72 \%$ of patients did not require supplementary injection, $69 \%$ did not require sedation and no patient required conversion to general anaesthesia.
\end{abstract}

Conclusion: Single injection inferonasal sub-Tenon's block is effective in $2 / 3^{\text {rd }}$ of patient undergoing PPV without requiring supplementary injection.

\section{Introduction}

Currently there are no specific guidelines concerning the safest and most efficacious mode of anaesthesia for patients undergoing Pars Plana Vitrectomy (PPV) and associated surgery. However, there is a recent Cochrane review comparing general versus regional anaesthesia [1]. Host of factors influence the specifics of PPV surgery resulting in varying preferences of anaesthesia and surgery. The choice of anaesthesia may be dictated by factors such as surgeon's preference, patient's age and preference as well as complexity of surgery, anticipated difficulty and duration of surgery [2-3]. Surgeon's preferences may be influenced by personal experience, availability of anaesthesia provider, influence of mentors, advances in technology, disease understanding, prevailing preferences of close colleagues, differential reimbursement incentives, instrument costs, personal attitude toward trying new approaches and bias [4].

Pars Plana Vitrectomy (PPV) and associated procedures (cataract surgery, scleral buckling etc.) have traditionally been performed under general anaesthesia which is more common in Europe than in the USA [4]. Patients requiring general anaesthesia tend to be younger; they are more likely to feel discomfort during regional anaesthesia and complete akinesia may not be achieved. Regional anaesthesia has increased in popularity in recent years [5-7]. Regional anaesthesia technique includes needle-based (retrobulbar and peribulbar) and cannula-based sub-Tenon's blocks. The use of topical anaesthesia (TA) in PPV surgery has been described [8] but shown to provide sufficient analgesia only in selected patients. Both retrobulbar and peribulbar blocks are used $[9,10]$ however, they are associated with the inherent increased risk of brainstem anaesthesia, retrobulbar haemorrhage and globe perforation - especially in long eyes and thinner sclera which may the case in patients undergoing PPV surgery [11]. Although needle-based blocks may provide anaesthesia duration ranging from $45-90$ minutes but they are considered unsuitable for subsequent supplementary injection due to changes in the shape of the globe which is altered intra-operatively following instrumentation.

Sub-Tenon's block requires incising the conjunctiva to gain access to the sub-Tenon's space and has been shown to be safer and effective block for vitreoretinal surgery $[10,12-14]$. This block has the advantages of avoiding serious albeit rare but well-known complications of the needle-based blocks [15]. The duration of anesthesia can be extended by simply injecting additional local anaesthetic agent through the initial dissection midway through the procedure on the operating table by the operating surgeon under sterile conditions [1]. Anaesthesia, akinesia and duration of sub-Tenon's block may be affected by several factors including the size of globe, orbital cavity, anaesthetic agent, volume, adjuvant and intraocular pressure lowering device [16,17]. There are wide variations in the volume of local anaesthetic agent used which ranges from $4-10 \mathrm{mls}[13,18]$. Both single or multiple sub-Tenon's injection techniques are in use [19] but we routinely use a single injection sub-Tenon's block for PPV and associated procedures. This

Correspondence to: Chandra M Kumar, Senior Consultant in Anaesthesia, Khoo Teck Puat Hospital, Yishun Central 90, Singapore 7688828, Tel: +6566022317; Fax: +65660237648; E-mail: Chandra.kumar2406@gmail.com

Key words: anaesthesia, regional, sub-Tenon's, subtenon, sub-tenon, $P P V$ vitrectomy

Received: September 17, 2017; Accepted: October 11, 2017; Published: October 13,2017 
prompted us to conduct a retrospective case record review to assess the utility and suitability of this technique as a primary method of anaesthesia for PPV and associated procedures. We collected data on onset of anaesthesia, duration of anaesthesia, supplementary injection requirement, sedation requirement, complications arising from block and surgeon's acceptability.

\section{Patients and methods}

Approval from Institutional Review Board (NHG/2015/00762) was obtained for a retrospective review of anaesthetic charts and operative databases of a cohort of consecutive patients undergoing PPV and associated procedures performed by a single surgeon from the year 2014 to 2015 in the Day Surgery Operating Theatre.

The sub-Tenon's block is routinely performed on the operating table irrespective of complexity of PPV procedures after attaching monitors (ECG, pulse oximetry and non-invasive blood pressure). Surface anaesthesia of conjunctiva and cornea is achieved by topical drops of tetracaine $1 \%$ followed a few drops of antiseptic solution $5 \%$ aqueous iodine for 3 minutes. Non-toothed Moorfields forceps is used to grip the conjunctiva and Tenon's capsule followed by a small incision with Westcott scissors to expose the white sclera in the inferonasal quadrant. Injection is performed using a blunt 19G, $25.4 \mathrm{~mm}$ long curved metal sub-Tenon's cannula with $6 \mathrm{mls}$ of $2 \%$ lignocaine and $10 \mathrm{IU} / \mathrm{ml}$ hyaluronidase. Honan balloon (intraocular pressure lowering device) is applied for 5 minutes after the injection. The onset of block (anaesthesia) is routinely assessed by observing the movements of the globe every 3 minutes in each direction of gaze (no movement, a flicker of movement, partial movement or full movement) after the removal of Honan's balloon. If muscle movements less than a flicker in all 4 gazes, anaesthesia is considered suitable for the surgery to start. If the muscle movements are more than a flicker after 11 minutes of initial injection, sub-Tenon's block is re-enforced with injection of $3 \mathrm{ml}$ of $2 \%$ lidocaine through the initial inferonasal dissection area. Supplementary oxygen is administered to all patients. Intraoperative supplementary injection (top-up) with $3 \mathrm{ml}$ of $2 \%$ lidocaine is administered by the operating surgeon when discomfort or pain is reported by the patient.

We collected patients' demography, onset of anaesthesia, start of surgery, duration of surgery, intraoperative supplementary injection/s, sedation and surgeon's acceptability of technique. Primary outcomes of this study to check if anaesthesia by single injection was of sufficient for the surgical procedure, need for supplementary injections as well as sedation. Data was entered in a Microsoft Excel spread sheet (Microsoft, Redmond, WA, US) and exported to the IBM SPSS Statistics program version 21.0 (IBM, Armonk, NY, USA). For each binary outcome, we used two sample t-test to compare the difference in continuous variables between the two groups of patients, and chi-square or Fisher's exact test if appropriate to test the association between categorical variables and the outcome. A p value of less than 0.05 was considered statistically significant.

\section{Results}

Records of 64 patients consisting of 27 females and 37 males were available for analysis. Their mean age was $58(\mathrm{SD} \pm 11)$ years old, mean height of $162(\mathrm{SD} \pm 9) \mathrm{cm}$, mean weight of $69.9(\mathrm{SD} \pm 13.1) \mathrm{kg}$, and mean body mass index of 26.9 (SD \pm 5.9$) \mathrm{kgm}^{-1}$. Five patients belonged to American Society of Anesthesiologist (ASA) physical status I, 31 patients ASA II and 28 patients ASA III. All patients achieved complete akinesia before the start of surgery. Twenty-eight percent of patients (18 out of the 64) required intraoperative supplementary injections and
$31 \%$ (20 out of the 64 ) required sedation. The overall mean block to start of surgery time was $17 \mathrm{~min}$ and the mean time from sub-Tenon's block to supplementary injection was $63 \mathrm{~min}$. There was no conversion to general anaesthesia.

Summary statistics comparing the group without supplementary injection versus the group with supplementary injection is shown in Table 1. Supplementary injections were more commonly employed in patients who required intraoperative gas $\left(\mathrm{C}_{3} \mathrm{~F}_{8}\right)$ by the operating surgeon ( $\mathrm{p}$ values $<0.001$ ). Surgery time was longer in the group with supplementary injections (96 min versus $85 \mathrm{~min}$ ) but this was not statistically significant. Use of sedation was no different in patients with or without supplementary injection.

Analysis of the subgroup of patients that received supplementary injections with or without sedation is shown below (Table 2). Longer surgery times was seen in the group that received both supplementary injection and sedation compared to those without sedation (119 min versus $84 \mathrm{~min}$, $\mathrm{p}$ value $=0.009$ ).

\section{Discussion}

This retrospective study shows that a single inferonasal sub-Tenon's injection with $6 \mathrm{mls}$ of $2 \%$ lidocaine and $10 \mathrm{IU} / \mathrm{ml}$ hyaluronidase provided sufficient duration of anaesthesia in $72 \%$ without requiring a supplementary injection in patients undergoing PPV and associated surgical procedures. Intraoperative supplementary injection was required in $28 \%$ of patients administered by the operating surgeon without any problem. The use of both supplementary injections and sedation were associated with longer duration of surgery. In addition, none of the cases required conversion to general anaesthesia. The surgeon was satisfied with the quality of anaesthesia and no complication related to sub-Tenon's block occurred.

Quality of anaesthesia, akinesia and duration of sub-Tenon's block may be affected by the size of globe, size of orbital cavity, local anaesthetic agent, volume, adjuvant administration and the use of intraocular pressure lowering device after the block [16,17]. Sub-Tenon's block is known to be effective but frequent intraoperative supplementary injections are required. In a study by Kwok and colleagues [20], 77\% patients required 1 or 2 supplementary injection when $4 \mathrm{mls}$ of 50:50 mixture of lidocaine $1 \%$ and bupivacaine $0.5 \%$ containing a total of $1200 \mathrm{IU}$ of hyaluronidase was administered through single inferonasal

Table 1. Summary statistics for supplementary injection versus no supplementary injection.

\begin{tabular}{|c|c|c|c|c|}
\hline & $\begin{array}{l}\text { All } \\
(n=64)\end{array}$ & $\begin{array}{l}\text { Supplementary } \\
\text { Injection } \\
(\mathrm{n}=18)\end{array}$ & $\begin{array}{l}\text { No } \\
\text { Supplementary } \\
\text { Injection } \\
(\mathrm{n}=46)\end{array}$ & p value \\
\hline Age & $58( \pm 11)$ & $57( \pm 11)$ & $59( \pm 12)$ & 0.730 \\
\hline $\begin{array}{l}\text { Gender } \\
\text { (Male:Female) }\end{array}$ & & $11: 7$ & $25: 21$ & 0.678 \\
\hline BMI $\left(\mathrm{kgm}^{-2}\right)$ & $26.9( \pm 5.9)$ & $27.3( \pm 6.7)$ & $26.7( \pm 5.7)$ & 0.749 \\
\hline \multicolumn{4}{|l|}{ ASA Score } & \multirow{4}{*}{0.912} \\
\hline I & $5(7.9 \%)$ & $1(5.6 \%)$ & $4(8.9 \%)$ & \\
\hline II & $30(47.6 \%)$ & $8(44.4 \%)$ & $23(50 \%)$ & \\
\hline III & $28(44.4 \%)$ & $9(50 \%)$ & $19(41.3 \%)$ & \\
\hline $\begin{array}{l}\text { Average } \\
\text { surgery } \\
\text { duration (min) }\end{array}$ & $88.3( \pm 30.4)$ & $95.6( \pm 28.9)$ & $85.3( \pm 30.8)$ & 0.231 \\
\hline $\begin{array}{l}\text { Block to } \\
\text { surgery start } \\
\text { time (min) }\end{array}$ & $16.8( \pm 5.6)$ & $17.2( \pm 4.3)$ & $16.6( \pm 6.0)$ & 0.729 \\
\hline Gas $\mathrm{C}_{3} \mathrm{~F}_{8}$ use & $12(19 \%)$ & $12(66.7 \%)$ & $0(0 \%)$ & $<0.001$ \\
\hline Sedation use & $20(31.7 \%)$ & $6(33.3 \%)$ & $14(31.1 \%)$ & 0.864 \\
\hline
\end{tabular}


Table 2. Subgroup of patients who received supplementary injections ( $\mathrm{n}=18)$.

\begin{tabular}{|c|c|c|c|c|}
\hline & All (18) & $\begin{array}{l}\text { Supplementary } \\
\text { injection \& } \\
\text { sedation } \\
(\mathrm{n}=6)\end{array}$ & $\begin{array}{l}\text { Supplementary } \\
\text { injection } \\
\text { without } \\
\text { sedation } \\
(\mathrm{n}=12)\end{array}$ & p value \\
\hline Age & $57( \pm 11)$ & $55( \pm 11)$ & $59( \pm 12)$ & 0.392 \\
\hline $\begin{array}{l}\text { Gender } \\
\text { (Male:Female) }\end{array}$ & $11: 7$ & $2: 4$ & $9: 3$ & 0.141 \\
\hline BMI $\left(\mathbf{k g m}^{-2}\right)$ & $27.3( \pm 6.7)$ & $27.7( \pm 8.6)$ & $27.0( \pm 5.9)$ & 0.855 \\
\hline ASA Score & & & & \multirow{4}{*}{0.294} \\
\hline I & $1(5.6 \%)$ & $1(16.7 \%)$ & $0(0 \%)$ & \\
\hline II & $9(50.0 \%)$ & $2(33.3 \%)$ & $7(58.3 \%)$ & \\
\hline III & $8(44.4 \%)$ & $3(50 \%)$ & $5(41.7 \%)$ & \\
\hline \begin{tabular}{|l} 
Block to \\
surgery start \\
time (min)
\end{tabular} & $17.2( \pm 4.3)$ & $17.5( \pm 6.1)$ & $17.0( \pm 3.4)$ & 0.825 \\
\hline $\begin{array}{l}\text { Average } \\
\text { surgery } \\
\text { duration (min) }\end{array}$ & $95.6( \pm 28.9)$ & $119.2( \pm 26.2)$ & $83.8( \pm 22.9)$ & 0.009 \\
\hline
\end{tabular}

sub-Tenon's injection. In another study, the number of supplementary injection was reduced to $37 \%$ when the volume of local anaesthetics agent was increased to $5 \mathrm{mls}$ containing 50:50 mixture of lidocaine $4 \%$ and bupivacaine $0.75 \%$ with hyaluronidase [18]. Gil et al [19] recently used $10 \mathrm{mls}$ of local anaesthetic agent (50:50 mixture of $2 \%$ lidocaine and $0.5 \%$ bupivacaine with 150 IU hyaluronidase) with two separate injections ( $5 \mathrm{mls}$ inferonasal and $5 \mathrm{mls}$ inferotemporal) in order to reduce the number of intraoperative supplementary injection. The authors managed to reduce the supplementary injection to zero. However, there are inherent increased risk of morbidities related to higher volume of local anaesthetic agent and multiple injections such as changes in shape and gaze of the globe, myotoxicity, proptosed orbit, conjunctival scarring and increased intraocular pressure. ${ }^{11}$ Rise in intraocular pressure can occur in patients with smaller orbital volume and tighter orbital septum - this commonly seen amongst the Asian population [21].

Our study has a few strengths and limitations. A standardized subTenon's block was used in all cases thus the influence of variation of anaesthesia technique was mitigated. The volume of local anaesthetic agent was $6 \mathrm{mls}$ in all cases, irrespective of the complexity of the surgical procedures. A single surgeon operated on all patients undergoing PPV and associated procedures thus reducing the bias and confounding effects of multiple surgeons and procedures. We routinely keep the use of sedation to a minimum and only administered in selected patients with severe anxiety or raised intraoperative blood pressure because sedation is known to influence the need for supplementary injection. This is a retrospective cohort study and not without limitations. The sample size was limited and we would have liked to include more surgeons. The observations from this study are limited to Asian patients. A large sample size, prospective, randomized, double blinded controlled trial comparing variations of volume and sub-Tenon's injections (single vs multiple) would be a more robust methodology, but may not be ethically and logistically feasible. Sub-Tenon's block is associated with minor and clinically insignificant but frequent complications such as chemosis and conjunctival haemorrhage [15]. Presence of swelling and haemorrhage of conjunctiva may deter some surgeons from advocating this method of anaesthesia. Akinesia scores and surgeon's satisfaction scores were not recorded in the anaesthetic chart. We accept the feedback of the operating surgeons on the quality of anaesthesia and this is supported by continued use of the subTenon's block for PPV surgery.
In conclusion, retrospective and non-comparative analysis of anaesthetic records and operative databases suggests that a single injection inferonasal sub-Tenon's block with $6 \mathrm{mls}$ of $2 \%$ lidocaine and $10 \mathrm{IU} / \mathrm{ml}$ of hyaluronidase aided with Honan's balloon provides anaesthesia and akinesia for sufficient duration in $2 / 3^{\text {rd }}$ of patients undergoing PPV surgery.

\section{Acknowledgment}

We are grateful to Dr Ajeet Wagle, Visiting Consultant Ophthalmologist, Khoo Teck Puat Hospital, Singapore for his help in performing supplementary injection on the operating table and surgeon's satisfaction assessment.

\section{References}

1. Licina A, Sidhu S, Xie J, Wan C (2016) Local versus general anaesthesia for adults undergoing pars plana vitrectomy surgery. Cochrane Database Syst Rev 9: CD009936. [Crossref]

2. El-Amir AN, Keenan TDL, Abu-Bakra M, Tanner V, Yeates D, et al. (2009) Trends in rates of retinal surgery in England from 1968 to 2004: studies of hospital statistics. $B r$ J. Ophthalmol 93: 1585-1590. [Crossref]

3. Isernhagen RD, Michels RG, Glaser BM, de Bustros S, Enger C (1988) Hospitalization requirements after vitreoretinal surgery. Arch Ophthalmol 106: 767-770. [Crossref]

4. D'Amico DJ (2016) Different preferences between United States and European vitreoretinal surgeons: personal observations. Curr Opin Ophthalmol 27: 196-200. [Crossref]

5. Sallam AAB, Donachie PHJ, Williamson TH, Sparrow JM, Johnston RL (2016) The Royal College of Ophthalmologists' National Ophthalmology Database Study of vitreoretinal surgery: report 5, anaesthetic techniques. Br J Ophthalmol 100: 246-252. [Crossref]

6. Costen MT, Newsom RS, Wainwright AC, Luff AJ, Canning CR (2005) Expanding role of local anaesthesia in vitreoretinal surgery. Eye (Lond) 19: 755-761. [Crossref]

7. Newsom R, Luff A, Wainwright C, Canning C (2001) UK survey of attitudes to local anaesthesia for vitreoretinal surgery. Eye (Lond) 15: 708-711. [Crossref]

8. Bahçecioglu H, Unal M, Artunay O, Rasier R, Sarici A (2007) Posterior vitrectomy under topical anesthesia. Can J Ophthalmol 42: 272-277. [Crossref]

9. Knight HM, Newsom RB, Canning CR, Luff AJ, Wainwright AC. (2001) Loca anaesthesia for vitreoretinal surgery: an audit of patient and surgical experience. Eur $J$ Ophthalmol 11: 366-371. [Crossref]

10. Li KZ, Tan CS (2016) Comment on visual impact of sub-Tenon anesthesia during combined phacoemulsification and vitrectomy surgery. Int J Ophthalmol 9: 323-324. [Crossref]

11. Kumar CM, Dowd TC (2006) Complications of ophthalmic regional blocks: their treatment and prevention. Ophthalmologica; 220: 73-82. [Crossref]

12. Roman SJ, Chong Sit DA, Boureau CM, Auclin FX, Ullern MM (1997) Sub-Tenon's anaesthesia: an efficient and safe technique. Br J Ophthalmol 81: 673-676. [Crossref]

13. Mein CE, Woodcock MG (1990) Local anesthesia for vitreoretinal surgery. Retina 10 47-49. [Crossref]

14. Lai MM, Lai JC, Lee W-H, Huang JJ, Patel S, et al. (2005) Comparison of retrobulbar and sub-Tenon's capsule injection of local anesthetic in vitreoretinal surgery. Ophthalmology 112: 574-579. [Crossref]

15. Kumar CM, Eid H, Dodds C (2011) Sub-Tenon's anaesthesia: complications and their prevention. Eye (Lond) 25: 694-703. [Crossref]

16. Patton N, Malik TY, Aslam TM, Vallance JH (2004) Effect of volume used in subTenon's anaesthesia on efficacy and intraocular pressure: a randomized clinical trial of $3 \mathrm{~mL}$ versus $5 \mathrm{~mL}$. Clin Experiment Ophthalmol 32: 488-491. [Crossref]

17. Schulenburg HE, Sri-Chandana C, Lyons G, Columb MO, McLure HA (2007) Hyaluronidase reduces local anaesthetic volumes for sub-Tenon's anaesthesia. $\mathrm{BrJ}$ Anaesth 99: 717-720. [Crossref]

18. Li HK, Abouleish A, Grady J, Groeschel W, Gill KS (2000) Sub-Tenon's injection for local anesthesia in posterior segment surgery. Ophthalmology 107: 41-46-47. [Crossref]

19. Gill VS, Presland AH, Lord JA, Bunce C, Xing W, Charteris DG (2012) Two-quadran high-volume sub-Tenon's anaesthesia for vitrectomy: a randomised controlled trial. $\mathrm{Br}$ J Ophthalmol 96: 189-192. [Crossref] 
20. Kwok AK, Van Newkirk MR, Lam DS, Fan DS (1999) Sub-Tenon's anesthesia in vitreoretinal surgery: a needleless technique. Retina 19: 291-296. [Crossref]
21. Sohn HJ, Moon HS, Nam DH, Paik HJ (2008) Effect of volume used in sub-Tenon's anesthesia on efficacy and intraocular pressure in vitreoretinal surgery. Ophthalmologica 222: 414-421. [Crossref]

Copyright: (C2017 Kumar CM. This is an open-access article distributed under the terms of the Creative Commons Attribution License, which permits unrestricted use, distribution, and reproduction in any medium, provided the original author and source are credited. 